Artículo Científico Original

Antoine Acker

\title{
TRABALHO FORÇADO NA FAZENDA DA VOLKS: CRÔNICA DE UM ESCÂNDALO AMAZÔNICO NA ALEMANHA
}


TRABALHO FORÇADO

NA FAZENDA DA VOLKS:

CRÔNICA DE UM

ESCÂNDALO AMAZÔNICO

NA ALEMANHA

Antoine Acker

\section{RESUMO}

Este artigo é dedicado ao escândalo de trabalho forçado relacionado com a fazenda amazônica Vale do Rio Cristalino, gerida pela firma alemã Volkswagen (VW) entre 1973 e 1986. As representações, a percepção e a recepção do escândalo na Alemanha constituem o ponto de enfoque do texto. $O$ objetivo deste artigo é triplo: explicar como uma multinacional de reputação moderna e humanista chegou a permitir uma gestão arcaica da mão de obra na própria fazenda, analisar o movimento de solidariedade trans-nacional que se desenvolveu na Alemanha em reação às notícias de trabalho forçado na "Cristalino", e avaliar o impacto dessa polêmica na conscientização ao nível internacional do problema de trabalho forçado amazônico.

Palavras-chave: Trabalho forçado, Amazônia, Volkswagen, Alemanha, solidariedade internacional
FORCED LABOUR IN THE VOLKSWAGEN RANCH: CHRONIQUE OF AN AMAZONIAN SCANDAL IN GERMANY

\section{ABSTRACT}

The object of this article is the scandal of forced labor linked to the Vale do Rio Cristalino Amazonian ranch, which belonged to the German firm Volkswagen (VW) between 1973 and 1986. Focusing on the representations, the perception and the reception of the scandal in Germany, this article has the following three aims:

- explaining how a multinational company of modern and humanist reputation could tolerate the existence of archaic forms of labor in its own ranch

-analyzing the movement of trans-national solidarity, which developed in Germany in reaction to the news of forced labor at "Cristalino"

-evaluating the impact of this polemic in the sensibilization, at the international level, as regards the problem of Amazonian forced labor.

Keywords : forced labour, Amazon, Volkswagen, Germany, international solidarity
Este artigo é dedicado ao escândalo do trabalho forçado relacionado com a fazenda amazônica Vale do Rio Cristalino, gerida pela firma alemã Volkswagen entre 1973 e 1986. As representações, a percepção e a recepção do escândalo na
Alemanha constituem o ponto de enfoque do texto.

A fazenda foi criada no sul do Pará e abrangia uma dimensão comparável à de alguns pequenos estados da República Federal da Alemanha (RFA). Era uma fa- 
zenda de gado onde havia também produção de madeira. Em 1976, quando o satélite americano Skylab identificou na Amazônia um incêndio de tamanho considerável, pelo qual a Cristalino era em parte responsável, a fazenda foi acusada de praticar um desmatamento abusivo e, a partir daí, se tornou um potencial objeto de críticas. Alguns anos depois, acusações de recurso à mão-de-obra forçada para as operações de desmatamento em Cristalino foram lançadas pela Comissão Pastoral da Terra (CPT). A informação foi difundida na Alemanha, em 1983 (Brasilien-Nachrichten (BN), 81/1983). Dentro da fazenda, existia um sistema segundo o qual os trabalhadores sazonais (os "peões") contratados por subempreiteiros da Volks ficavam endividados de diversas formas (engano nos salários, pagamento de preços desonestos por diversos serviços fornecidos pelos empreiteiros, entre outros), eram mantidos dentro da fazenda durante vários meses sem poder fugir e eram ainda submetidos à violência de guardas ("os gatos"), que cometiam contra eles sevícias físicas e morais (Le Breton, 2003, p. 147-60).

Embora tenham sido poucos os autores a interessar-se pelo assunto, as suas características essenciais já foram apontadas (Ibid.; Rezende, 2000; Buclet, 2005):

- O paradoxo de um tratamento de mão de obra arcaico que era utilizado por uma empresa de grande dimensão que representava o capitalismo moderno;

- a dimensão internacional dos acontecimentos quer devido às origens multinacionais dos investimentos quer devido aos protestos que tal projecto suscitou;

- o fato de a divulgação da história específica da fazenda Cristalino ter sido uma etapa importante na divulgação do problema mais geral do trabalho forçado contemporâneo no Brasil.
Estas foram as reflexões que orientaram este texto, que foi desenvolvido a partir de três questões com elas relacionadas e que se focaram, sobretudo, no lado alemão dos debates em torno da fazenda Cristalino:

1) Como se tornou possível uma empresa como a VW, modelo da "economia social de mercado" alemã, ver-se envolvida num grave processo de exploração humana?

2) Poderá considerar-se a coligação que agiu contra a Volks e que agiu não só no país dos acontecimentos mas também no país de origem da empresa um modelo de resistência aos abusos das multinacionais?

3) Terá a mediatização do assunto "Cristalino" na Alemanha ajudado a sensibilizar o país em torno do fenômeno do trabalho forçado contemporâneo no campo, um fenômeno então ainda pouco conhecido na Europa?

\section{Longe da "Fazenda Modelo" de Wolfsburg, a "fazenda invisível" dos trabalhadores sazonais}

Desde o início, a operação de Volkswagen na Amazônia foi, sobretudo, um meio para evitar que uma parte dos benefícios da empresa acabesse gasta com taxas públicas. $\bigcirc$ governo brasileiro, no âmbito da sua nova política de desenvolvimento da Amazônia, distribuía incentivos fiscais generosos a investidores que tinham projetos pela região. Os representantes da empresa nunca esconderam essa motivação lucrativa às autoridades alemãs. No entanto, é impossível resumir o projeto Cristalino por este só objetivo de lucro. Os textos difundidos pela Volkswagen mostram que a companhia se sentia investida de uma missão ideológica consistindo em importar uma cultura de "modernidade" nos "países em desenvolvimento" (Volkswagen A.G., 
1980). Autoproclamando-se líder industrial do desenvolvimento, a Volks justificava os seus investimentos em países como o Brasil, o Mexico ou a África do Sul através de uma retórica filantrópica que fazia da empresa o "parceiro do mundo", o agente da "ajuda ao desenvolvimento no sentido mais nobre do termo" (Ibid.). É nesse âmbito que se pode entender a apresentação do projeto de fazenda ao público alemão. Já que a empresa queria fazer de Cristalino um exemplo do seu desempenho em favor do "terceiro-mundo", distibuiu à imprensa alemã numerosos folhetos promocionais pelo lançamento da operação e também ao longo do seu processo de consolidação (Ibid.; Autogramm, 19/12/1973-01/10/1985 (dez edições); Frankfurter Allgemeine Zeitung, 25/09/1979; Volkswagen do Brasil S.A., 1983; Volkswagen, arquivos de empresa). Em 1980, VW até produziu um filme documentário dedicado à fazenda, distribuido nas escolas da Alemanha Ocidental e acompanhado de um caderno didático dirigido aos professores (Richter, 1980). Todos esses documentos apresentavam a fazenda como um projeto de excepcional modernidade, elaborado com a ajuda de técnicos europeus e americanos de alto nível. A ambição era fornecer uma contribuição decisiva para nada menos que a modernização de uma região - a Amazônia - "às margens da civilização", o desenvolvimento econômico do Brasil e a erradicação da fome no país graças à melhoria das técnicas de criação de boi (Brügger, 1985; Volkswagen A.G., 1980).

Volkswagen elogiava também a situação exemplar dos seus empregados em Cristalino. Teriam sido liberados do seu "modo de vida vagabundo" para ser alojados em confortáveis casas de alvenaria, receber uma remuneração "bem mais elevada" do que o mínimo legal brasileiro, e aproveitar de serviços e infrastruturas exemplares (Richter, 1980, p.12-4): alojamento gratuito, piscina, terreno de esporte, bar, escola, supermercado moderno, entre outras "vantagens". Esta ideia de uma relação privilegiada entre a empresa e os seus empregados, baseada num tratamento humanista dos trabalhadores, constituia um elemento central da comunicação da Volkswagen, a partir do qual a companhia já tinha construído a sua reputação na Alemanha (Doleschal e Dombois, 1982). A atribuição de salários generosos, a oferta aos operários de serviços disponíveis fora do tempo de trabalho e a segurança do emprego já faziam parte da imagem positiva de VW na Alemanha Federal. A companhia apresentava-se como um modelo da "soziale Marktwirtschaft" (economia social de mercado) ou, por outras palavras, de um capitalismo beneficiando também os operários. Uma imagem semelhante era difundida a propósito das fábricas brasileiras da Volks em São Bernardo do Campo, no Brasil (Volkswagen A.G., 1973).

No entanto, vários pesquisadores já mostraram que essa generosidade frente aos assalariados, apesar de ser fundamental na reputacão da Volkswagen, tanto na Alemanha como no Brasil, abrangia só uma elite minoritária de operários. A partir do meio dos anos 1970, a produção de automóvel ficou cada vez mais transferida para uma mão de obra periférica - baseada em empregos precários e disponível pelas tarefas menos especializadas - ou externa - contratada por sub-empresários, geralmente com baixa remuneração e fraca proteção social (Gorz, 1988, 110-5; Kern e Schumann, 1984). Em resumo, já na época da fazenda Cristalino, a comunicação humanista da VW se apoiava na representação de um círculo limitado de operários, beneficiado por direitos superiores à média. Ao mesmo tempo, a maior parte da producão era efetuada por uma mão-de-obra "invisível", ausente da propaganda 
da empresa e sem representacão sindical direta, pelo fato de os contratos serem precários e de os contratados terem um fraco nível de instrução e informação. Würtele e Lobgesang explicam como, nos anos 1970, Volkswagen aplicava a mesma estratégia comunicativa tanto no Brasil como na Alemanha: a promoção publicitária de uma política empresarial favorável a uma minoria privilegiada de operários, apesar da existência não ou pouco mencionada de uma mão de obra sub-contratada, efetuando os trabalhos menos qualificados, no âmbito de um regime social mínimo (Würtele e Lobgesang, 1979).

Uma representação semelhante pode ser observada na imagem da fazenda que a Volkswagen propunha ao público alemão: a empresa elogiava as vantagens atribuídas aos 380 empregados regulares da fazenda - vaqueiros, mecânicos, operários da produção de madeira, administração - e às suas famílias. Mas, a grande maioria dos indivíduos inscritos no domínio de Cristalino nem era sequer mencionada nos documentos públicos. Essa maioria era composta pelos trabalhadores sazonais, responsáveis pelas "baixas tarefas" de desmatamento. Por definição, o número de sazonais evolvia irregularmente em função dos períodos. Em 1983, por exemplo, teria havido mais de um milhar de trabalhadores sazonais na estação mais favorável pelas atividades de desbravamento (BN, 93/1986). Eram contratados por sub-empreteiros. A realidade dos seus tratamento e salário não era conhecida em Wolfsburg. O sentimento de responsabilidade da multinacional no que diz respeito às condições de trabalho desses operários era inexistente.

Essa dualidade de tratamento entre diferentes classes de operários rurais foi observada por uma visitante da fazenda, a jornalista do Spiegel, Ariane Barth, em 1983:
Há também as baracas lamentáveis dos trabalhadores que se ocupam da derrubada [..]. A pobreza dessa gente não faz parte do programa da visita. Os 800 trabalhadores florestais de Cristalino vivem fora da infrastrutura social, criada para os empregados que moram nas belas casinhas de telha, com eletricidade e água corrente. É comum que as classes desfavorecidas da Amazônia [...] se vendam a uns "Gatos", e esses "Gatos" [...] vendem um serviço de desbravamento. Assim, VW não se preocupa desses trabalhadores em aluguel. São os Gatos que são responsáveis deles. [...] Enquanto representante de uma empresa estrangeira, o Brügger (o manager suiço da fazenda Cristalino) preserva-se de qualquer contato direto com esse proletariado que, sem traço escrito na burocracia, não tem existência cívica (Der Spiegel, 17/10/1983 - nossa tradução).

Havia então, por um lado, a fazenda modelo elogiada na comunicação da Volkswagen na Alemanha, com assalariados beneficiados por condições sociais de alto nível. E havia, por outro lado, a fazenda invisível dos trabalhadores sazonais e anónimos. Essa fazenda invisível não era incluída nem evocada na retórica de ajuda ao desenvolvimento que a Volks espalhava no âmbito dos seus investimentos em países do Sul tal como o Brasil.

\section{Uma "responsabilidade alemã"? Escândalos e críticas contra o projeto Cristalino}

A fazenda invisível dos "peões" e dos "gatos", que funcionava graças a um sistema de trabalho forçado por dívida mantida através da violência e da intimidação, devia, porém, sair do anonimato. Isso foi feito nomeadamente graças à 
ação da Comissão Pastoral da Terra (CPT) e do seu representante local na região da fazenda, o Padre Ricardo Rezende Figueira, que tornou públicas as acusações contra a Companhia Rio Cristalino, depois de ter recolhido depoimentos das vítimas. No dia 7 de maio de 1983, Rezende fez uma primeira conferência de imprensa em Brasília (BN, 81/1983). Logo na semana seguinte, um artigo da Agence France Presse (AFP), relatando os fatos, foi transcrito nos jornais europeus (Frankfurter Rundschau, 11/5/1983). Dado o escândalo ambiental ocorrido em 1976 na Cristalino, a atencão mediática para as atividades de Volkswagen na Amazônia ainda estava bastante viva, o que permitiu às acusações da CPT não serem ignoradas e chegarem na Alemanha num prazo rápido.

Podem-se identificar três grupos de agentes na Alemanha, cuja ação possibilitou fazer conhecer o comprometimento do grupo Volkswagen com práticas análogas às da escravidão contemporânea. Possibilitou também influenciar a política da empresa e, sem dúvida, contribuir para provocar a venda da fazenda Cristalino no final do ano de 1986. O primeiro grupo era um agrupamento amorfo de militantes interessados no problema da justiça social na América Latina e conhecedores das problemáticas desta região do mundo. O segundo grupo juntava atores próximos à igreja católica, animados com um forte desempenho social e considerando como o seu dever de serem os porta-vozes dos pobres frente à todo poderosa VW (Recklinghäuserzeitung, 01/12/1982). Enfim, o último grupo, heterogéneo, compreendia atores de primeiro plano, geralmente menos especializados no problema em questão (exploração e desigualdades no norte Brasileiro), mas dispondo de uma influência direta na opinião pública e nos meios de poder.
1. Os grupos de solidariedade com a América Latina

São esses grupos que mais se interessaram pelo caso Cristalino. Trata-se de associações, de círculos de reflexão ou de simples redes de intercâmbio cujos membros conheciam bem o Brasil ou outros países da América Latina. Essas pequenas unidades, compreendendo latino-americanos, inteletuais especialistas da região, ativistas de esquerda, às vezes marxistas, interessados pela teologia da libertação ou pela emergência dos movimentos dos sem-terra, conheceram a sua idade de ouro nos anos 1970 e 1980. Tinham-se desenvolvido no início dos anos 1970, na onda dos "Novos Movimentos Sociais", que tinham trazido à politica e nas lutas associativas a ideia da responsabilidade alemã nos países do sul, do combate contra o neocolonialismo e de uma solidariedade com os diferentes povos do mundo. Esses grupos difundiam as suas ideias através de jornais com tiragem moderada (em geral alguns milhares de exemplares) mas gozando de uma boa audiência nos meios académicos, especializados ou ativistas. Entre essas publicações se podem mencionar: BrasilienDialog, uma publicação cristão de esquerda; o centro de Informação América Latina (Informationsstelle Lateinamerika ILA), cujos representantes escreveram à Volkswagen para pedir explicações sobre o trabalho forçado (BN, 81/1983); a foIha Brasilien-Infos; e, sobretudo, BrasilienNachrichten (Notícias-Brasil, BN), a revista da associação Brasilieninitiative, sediada em Friburgo, que liderou a campanha para por fim às práticas de trabalho forçado na fazenda Cristalino.

Fundada em 1978, Brasilieninitiative era uma associação regrupando alemães e brasileiros militando na solidariedade transcontinental e mantendo contatos com os movimentos sociais brasileiros (CPT, 
sindicatos de trabalhadores rurais, movimentos ameríndios). Um dos seus membros, Peter Klein, redator da B-N, dispunha, como o atesta a sua correspondência epistolar com Ricardo Rezende e as suas publicações no jornal, de múltiplos contatos, não só nos meios ativistas brasileiros mas também em setores importantes das elites alemãs. Klein era também um dos coordenadores da secção "Brasil" de Amnesty International na Alemanha. Essa posição servia-lhe de alavanca para influir nos meios políticos. Ajudada pelas redes de Klein, a B-N forneceu um trabalho notável para fazer avançar o caso. De 1978 a 1987, o jornal não parou de investigar sobre Cristalino e de informar - público mais amplo possível sobre as atividades da VW no Brasil. Dois jornalistas foram mandados ao local para visitarem a fazenda. Numerosos atores políticos e associativos de primeiro plano foram entrevistados no Brasil, documentos foram distribuídos a atores suscetíveis de ajudar na resolucão do problema na Alemanha, como o partido dos Verdes (Die Grünen) (BN, 1983 a 1986). Além disso, Brasilieninitiative manteve a pressão sobre a multinacional automóvel, pedindo-lhe regularmente para tomar posição no que dizia respeito ao desenvolvimento das investigações da B-N. Por fim, a associação sempre trabalhou em colaboração com Ricardo Rezende, transmitindo-lhe regulares traduções, para que a CPT pudesse ficar informada das evoluções do debate na Alemanha. Precisamente, em 1985 Brasilieninitiative organizou em Friburgo uma reunião pública intitulada: "Corresponsabilidade das empresas estrangeiras - Escravidão na fazenda de VW?". O convidado especial da reunião era Ricardo Rezende, que aproveitou a oportunidade para se exprimir sobre $\circ$ assunto de maneira detalhada (Freiburger Zeitung, $21 / 10 / 1985)$.

\section{Os círculos cristãos}

Os atores cristãos católicos interessaram-se rapidamente pelos problemas postos pelos investimentos de VW na Amazônia. Apesar de a sua ação contra a Volks não ser de natureza diretamente religiosa, o fato desses atores ostentarem a sua filiação religiosa era um elemento importante por duas razões: em primeiro lugar porque essa filiação explica o interêsse por e as conexões com atores da teologia da libertação no Brasil. Em segundo lugar, porque a sensibilidade "cristã" conferia um contrapeso aos numerosos apoios "cristãos" que agiam em favor da companhia. Por exemplo, o partido Cristão-Democrático no poder, a CDU, era muito favorável ao projeto Cristalino, e os seus representantes tinham um peso decisivo nos orgãos dirigentes de VW (Der Spiegel, 19/11/1973). A própria empresa de automóvel dizia que seguia a ética cristã nas suas ações (Hornig e Wetzel, 1983). Era, então, importante demonstrar que também dentro da Igreja havia vozes que criticavam os abusos da VW na Amazônia. Além disso, a empresa, já que proclamava a sua ligação com os valores cristãos, não podia ignorar as interrogações vindas de padres ou de ativistas ligados a paróquias.

$\mathrm{Na}$ paróquia de St. Peter em Recklinghausen (Renania do Norte Westafalia), uma associação católica de solidariedade com o Sul começou já no início dos anos 80 uma longa série de ações com o objetivo de esclarecer as "zonas de sombra" do percurso de sucesso da VW no Brasil (Hax-Schoppenhorst e Möller, 1999). A associação chamava-se Arbeitskreis Dritte Welt (Círculo de Trabalho Terceiro-Mundo). Os investimentos da empresa na Amazônia atraíram a curiosidade dos ativistas de St. Peter, que não acreditavam na viabilidade do projeto e puseram em questão a sua preten- 
dida motivação filantrópica. Para eles, a custosa produção de boi em Cristalino não respondia às necessidades do mercado brasileiro, gerava poucos empregos e era secretamente destinada à exportação: em consequência, não se podia tratar de um projeto humanista dedicado à luta contra a fome. Em 1982, o Arbeitskreis convidou os representantes de Volkswagen a uma discussão pública com $\circ$ padre da paróquia em Recklinghausen, para lhes expor as dúvidas que a associação tinha sobre $\bigcirc$ projeto (Recklinghäuserzeitung, 01/12/1982). A reunião se concluiu de maneira conflituosa e Wolfsburg até ameaçou acabar o diálogo com a paróquia. No entanto, o pedagogo e ensaísta Thomas Hax que era uma das figuras da paróquia St. Peter, continuou a comunicar com a Volkswagen até o verão de 1983, reclamando que a empresa esclarecesse as suspeitas que pesavam sobre a fazenda (Arbeitsgruppe Brasilien, 1984, 32-35). Ele pediu também publicamente aos alemães que boicotassem os produtos VW. Mas, depois do escândalo de trabaIho forçado, a tensão ficou muito elevada entre Hax e a Volkswagen, que decidiu romper definitivamente a comunicação com a paróquia St. Peter (Ibid.).

A ruptura entre St. Peter e VW não foi suficiente para impedir que atores cristãos se interessassem pelo problema. Assim, a revista cristã Publik-Forum, tiragem de 20.000 exemplares, consagrou dois grandes artigos às práticas "escravagistas" (pelo menos assim chamadas por numerosos ativistas) da VW. Em 1985, a vinda de Ricardo Rezende na Alemanha, durante a qual o padre deu várias conferências e reuniões públicas sobre o conflito da terra na região de Cristalino, inclusive abordando o caso da Volkswagen, marcou uma nova etapa na legitimidade das críticas (Freiburger Zeitung, $21 / 10 / 1985$ ). Já alguns meses antes, o bispo do Araguaia, Dom Patrício Hanrahan, tinha viajado à
Alemanha e entregado à conferência episcopal alemã, em Colónia, um dossiê de documentos comprovando as acusações contra a "Volks" (BN, 81/1983). Ao longo dos anos 1980, a credibilidade do movimento de protesto contra a fazenda VW foi sempre consolidada pelas intervenções de atores provindos da igreja. Por isso, não é surpreendente que a oposição associativa (por exemplo Brasilieninitiative) e política (os Verdes) à VW se tenha regularmente referido às posições de padres para legitimar as acusações de trabalho forçado proferidas contra a companhia multinacional (Die Grünen Informieren, 12/12/1985; Niedersäschsischer Landtag, 1985).

\section{Os atores de primeiro plano}

Graças ao trabalho dos ativistas de solidariedade com a América Latina (grupo 1) e dos militantes "cristãos" (grupo 2), conhecedores das realidades brasileiras e intensivamente mobilizados, as informações e os esclarecimentos sobre o "caso Cristalino" atingiram também, num segundo tempo, círculos mais amplos, através de atores beneficiados por contatos com o público. Os artigos de B-N ou as publicações do Arbeitskreis Dritte Welt de St. Peter atraíram os jornalistas. Vários jornalistas até tiveram a curiosidade de visitar a fazenda. Grandes revistas de reputação internacional como o Los Angeles Times, o Times ou Der Spiegel publicaram reportagens sobre o assunto, nos quais a temática dos "peões" e dos "gatos" era evocada, mesmo se não explicada suffcientemente (Der Spiegel, 17/10/1983; Times, 10/05/1983). Enfim, em 1985, as acusações foram trazidas até os meios políticos através de uma iniciativa dos Verdes alemães (Die Grünen Informieren, 12/12/1985; Niedersäschsischer Landtag, 1985). O partido endereçou uma "grande questão" ("grosse Anfrage") 
pública ao ministério das finanças do estado de Baixa Saxônia, maior accionista de VW, corresponsável pelo funcionamento da fazenda. Seguiu um debate parlamentar durante o qual os Verdes se opuseram à CDU e ao FDP, o partido liberal. Esse debate simbolizou uma nova etapa na sensibilização das elites políticas sobre o problema da responsabilidade alemã em fenómenos de exploração na Amazônia. Mas, o desenvolvimento da discussão foi muito genérico e o fenômeno do trabalho forçado contemporâneo foi pouco abordado nos detalhes pelos deputados. Pode-se constatar, então, que se "atores de primeiro plano" conhecidos do público, como os Verdes ou a mídia de larga tiragem, permitiram difundir as críticas contra Cristalino, ao mesmo tempo a sua falta de especialização no tema do trabalho forçado e nas realidades brasileiras constituiu um obstáculo à compreensão do assunto na Alemanha.

Além disso, os partidos políticos e os grandes jornais, contrariamente aos pequenos círculos de militantes identificados nos grupos 1 e 2, têm que cumprir obrigações de rentabilidade, seja em termos econômicos (para a imprensa) seja em termos eleitorais (para os Verdes). Esses atores tendem a adaptar o seu discurso às expectativas do público mais do que levar o público a áreas de reflexão difíceis e pouco conhecidas. Por isso, esses atores evocaram raramente em detalhe o problema do trabalho forçado por dívida. Em geral, o enfoque foi posto na temática da deflorestação e da destruição ambiental, mais familiar ao público alemão e europeu. Assim, numerosos atores importantes (a revista Natur, o grupo de imprensa Horst Stern, a revista científica vernácula GEO, ou ainda o conhecido jornal inglês The Ecologist) denunciaram as atividades de exploração ambiental em Cristalino sem sequer evocar a existência de trabalho forçado na fazenda.
Globalmente, houve poucas tomadas de posição para tematizar ambos os problemas ambientais e sociais ligados ao projeto da "Volks" e estabelecer um vínculo entre a exploração dos trabalhadores rurais e a destruição da mata.

\section{A reação às críticas contra Cristalino}

Frente às acusações de escravidão, uma coligação se organizou na Alemanha para defender os interesses do "modelo Volkswagen". É útil precisar que com a Volkswagen, não se tratava de qualquer empresa, mas sim de uma entidade profundamente enraízada na história, economia e cultura do país, vínculada financeiramente com a RFA através dos capitais do Estado federal (20\%) e do Estado de Baixa-Saxônia (20\%) (Doleschal e Dombois, 1982). A firma era administrada conforme um sistema específico de blocagem que a colocava sob a influência direta dos poderes públicos, apesar de esses últimos não disporem da maioria absoluta do capital empresarial. As atividades da Volkswagen e de outras grandes empresas alemãs no estrangeiro constituíam uma parte importante, senão central, da política de ajuda ao desenvolvimento da RFA, gigante econômico, mas anão político e militar no plano internacional. A imagem de VW no mundo era, então, ligada à imagem da própria Alemanha. Existia um consenso nacional sobre a política de "ajuda ao desenvolvimento" da Volkswagen, e a fazenda Cristalino constituía um verdadeiro símbolo disso, já que tinha sido comprada com o apoio dos três maiores partidos do país, depois de uma viagem no Brasil efetuada por um representante da CDU e um outro do partido social-democrático SPD, que eram também membros do conselho de administração da companhia de automóveis (Der Spiegel, 19/11/1973; Die Zeit, 14/12/1973). 
Nesse contexto, não é particularmente surpreendente que muitos atores de poder se tenham mobilizados a partir de 1983 para salvar a imagem da Volkswagen perante as acusações de escravidão contemporânea na fazenda Cristalino, como se quisessem, através disso, salvar também a imagem da Alemanha. Entre eles, havia o governo de Baixa-Saxônia, a CDU e o FDP, o jornal conservador Die Welt (várias centenas de milhares de exemplares), os meios de negócios alemães próximos ao Brasil (nomeadamente pelo jornal Cadernos Germano-Brasileiros / Deutsch-brasilianische Hefte), a embaixada alemã no Brasil, que afirmou o seu apoio total à empresa e também uma parte da igreja católica alemã: Jürgen Aretz, representante dos bispos alemães na Conferência Episcopal da RFA foi visitar a fazenda, que julgou positivamente (Die Welt, 13/05/1983). Ao mesmo tempo, culpou os elementos "progressistas" da Igreja Brasileira por serem demasiado interessados no "engajamento social", até esquecerem o seu "dever pastoral". Os defensores da Volkswagen rejeitavam a responsabilidade da companhia nos escândalos acontecidos em Cristalino e explicavam que as acusações eram somente o resultado do ressentimento da esquerda brasileira contra as empresas estrangeiras. Para Die Welt, o "affarão Cristalino" era infundado e representava só uma nova oportunidade para fazer das multinacionais o bode expiatório dos problemas do Brasil (Ibid.). Frente à "vã polémica" e aos "agitadores", os membros da CDU e do FDP insistiam no papel positivo das empresas alemãs no Brasil, dizendo que eram o "motor do progresso social" (Niedersächsischer Landtag, 1985). "Difamar Volkswagen", para a bancada do FDP no parlamento de Baixa-Saxônia, significava atacar uma empresa dedicada ao interesse dos trabalhadores alemães e humilhar toda a economia alemã. Para a CDU, o ataque contra Cristalino era uma demonstração da "maneira insuportável" como as empresas alemães eram "discriminadas no segundo e no terceiro mundo" (Die Welt, 13/05/1983).

A estratégia de defesa da Volkswagen e dos seus aliados consistiu em negar todas as acusações de exploração de trabalhadores sazonais, insistindo na reputação e na credibilidade da empresa e reduzindo os adversários ao estatuto de simples polemistas, politizados à esquerda e, então, desfavoráveis "a priori" ao mundo empresarial e incapazes de ver a realidade com objetividade. A legitimidade dos oponentes também era regularmente contestada. "Die Welt", por exemplo, afirmava que Rezende era um "desconhecido", enquanto Volkswagen o apresentava como um indivíduo desonesto abusando da sua função de padre (Ibid.). Os representantes da empresa foram ainda mais hostis contra Thomas Hax, comparando-o aos "destruidores históricos do pensamento cristão" (Hornig e Wetzel, 1983). Para a VW, as acusações emitidas contra Cristalino não eram comprovadas, mas sim difundidas na base de falsos testemunhos e de rumores (Arbeitsgruppe Brasilien, 1984, p.31-5). A empresa ignorou todos os documentos produzidos pelas autoridades oficiais, como os relatórios de polícia. Quando uma comissão composta por parlamentares de São Paulo foi investigar na fazenda e confirmou a existência de tratamentos violentos assim como a responsabilidade da Volkswagen nesses fatos, a companhia fingiu entender exactamente o contrário. Malgrado um desmentido público (feito na $\mathrm{B}-\mathrm{N}$ ) do redator do relatório, o deputado estadual Expedito Soares (PT), a "Volks" continuou a estimar-se inocentada pela comissão de investigação (BN, 84/1984; $93 / 1986)$. Frente ao estatuto prestigioso da Volkswagen na Alemanha, as palavras dos ativistas, dos padres ou mesmo 
de um deputado de esquerda tinham pouco peso, assim como o mostra essa declaração do ministro das financias da Baixa-Saxônia: "Para mim as afirmações de um empresário bem-sucedido e que dirige a Volkswagen do Brasil [Wolfgang Saver], têm muito mais peso do que todas as polémicas que podem ser lançadas, em qualquer lugar do mundo que seja" (Niedersächsicher Landtag, 1985).

Apesar destes prestigiosos apoios, a empresa começou a mostrar sinais de fraqueza, em particular no tom cada vez mais agressivo do seu discurso. Nas cartas do serviço de relações públicas de Wolfsburg, pode-se constatar, a partir do final de 1983, a expressão de um crescente nervosismo. Tornaram-se cada vez mais frequentes por parte da empresa as rupturas de diálogo, as acusações de mentiras, as ameaças - nunca aplicadas - de ações judiciárias contra os oponentes associativos e a utilização de qualificações extremamente duras. Esse clima de tensão manteve-se até que a fazenda foi vendida pela empresa no final do ano de 1986 (Arbeitsgruppe Brasilien, 1984, p.31-5; Strömel e Hertel, 1985). Oficialmente, foi a criação de uma holding com a Ford do Brasil que obrigou a Volkswagen a acabar com Cristalino a fim de liberar créditos (Doleschal, 1987, p.133; Autogramm, jan. 1987). Mas será realmente possível acreditar que, depois de treze anos de publicidade intensiva, o "Pilotprojekt" da multinacional alemã tenha sido de repente liquidado a favor de novas atividades? $O$ contexto dessa venda, três anos depois da revelação internacional da existência de uma mão de obra não livre em Cristalino, pode levar a outra conclusão. É possível considerar, como o sugere o jornalista suiço Luc Banderet num comentário comunicado à CPT, que o fim do "ranch Volkswagen" foi, sobretudo, um fim político.

\section{Elementos de conclusão:}

É certo que considerar somente o contexto alemão não basta para entender a complexidade do "assunto Cristalino" que, apesar de ter tido uma dimensão transnacional, contém particularidades enraizadas na sociedade e na história brasileiras. No entanto, uma análise da repercussão do escândalo na Alemanha permanece uma etapa indispensável para esboçar uma história da fazenda, e nos possibilita sugerir hipóteses preliminares de resposta às interrogações evocadas na introdução deste texto:

1) A oposição entre o capitalismo moderno e de reputação humanista da VW e - facto de uma mão de obra não livre ter existido numa fazenda da mesma firma não deixam de surpreender. Mas é em parte explicável se tivermos em conta a estratégia empresarial da Volks na organização da sua produção, tanto na Alemanha como no Brasil. Essa estratégia é caraterizada por uma desresponsabilização da Volks relativamente à mão de obra não especializada, cuja gestão costumava ficar a cargo de subempreiteiros, que eram deixados praticamente sem controle por parte da multinacional de automóvel com a finalidade de manter baixos os custos de produção.

2) Perante a desresponsabilização da Volks vis-a-vis uma parte da mão de obra em Cristalino, constituiu-se uma coligação de protestos na Alemanha, articulada por contatos com atores político-associativos brasileiros. $O$ trabalho desses ativistas permitiu uma larga difusão das informações e uma pressão contínua e intensa contra a sede da VW em Wolfsburg. Essa pressão contribuiu para convencer a empresa a vender a fazenda. A multinacional, porém, continuou a negar os fatos censurados e não reformou a estrutura de produção na fazenda antes de abandoná-la. 
3) A chegada do escândalo "Cristalino" à Alemanha atraiu um certo interesse para as temáticas amazônicas e incentivou a publicação na mídia de vários artigos sobre temas -as vezes somente vagamente - relacionados (direitos dos Índios, desmatamento, etc.). Infelizmente, houve um fraco esclarecimento acerca do próprio tema do trabalho forçado por dívida, apesar dos esforços de grupos pequenos como a Brasilieninitiative. O discurso generalista da grande mídia, a existência de um apoio importante em favor da Volks nas elites alemãs e a atitude de negação da empresa não ajudaram a uma clara identificação e compreensão por parte do público dos crimes atribuídos à VW.

\section{BIBLIOGRAFIA}

\section{Literatura}

ARBEITSGRUPPE BRASILIEN. 1984. Die Farm Am Amazonas: Von Volkswagen Lernen. Bielefeld, Dritte Welt Haus E.v.

DEUTSCHER BUNDESTAG. 1974. Ausschuss für Wirtschaftliche Zusammenarbeit des Deutschen Bundestages. 31. und 32. Sitzung. Öffentliche Anhörung von Sachverständigen über das Thema "Tätigkeit und entwicklungspolitischer Einfluss deutscher multinationaler Unternehmen in Entwicklungsländern". Bonn, Deutscher Bundestag.

BUCLET, B. Entre Tecnologia E Escravidão: A Aventura Da Volkswagen Na Amazônia. Revista do Programa de Pós-Graduação em Serviço Social da PUC-Rio, 13(1): Disponível em:<http://www.gptec.cfch.ufrj.br/pdf/tecnologia_escravidao.pdf $>$. Acessado em 01/02/2010.

DOLESCHAL, R.; DOMBOIS, R. (Org.). 1982. Wohin läuft VW? die Automobilproduktion in der Wirtschaftskrise. Reinbek, Rowohlt.

DOLESCHAL, R. 1987 Automobilproduktion und Industriearbeiter in Brasilien: eine Untersuchung über Volkswagen do Brasil und die internationale Arbeitsteilung. Saarbrücken, Breitenbach.
GORZ, A. 1988. Métamorphoses du travail. Critique de la raison économique. $2^{a}$ ed., Paris, Gallimard.

HAX-SCHOPPENHORST, T.; MÖLLER, P. 1999. Nestverweis für Schräge Vögel. Der Ak 3. Welt St.Peter verläßt nach 27 Jahren die Gemeinde. In: N. METTE; L. WECKEL; A. WINTELS (org.), Brücken und Gräben. Sozialpastorale Impulse und Initiativen im Spannungsfeld von Gemeinde und Politik. Münster, LIT, p.68-76.

KERN, H.; SCHUMANN, M. 1984. Ende der Arbeitsverteilung? Munich, C.H. Beck.

LE BRETON, B. 2003. Trapped: Modern-Day Slavery in the Brazilian Amazon. Londres, Kumarian Press.

REZENDE FIGUEIRA, R. 2000. Por que o trabalho escravo? Estudos Avançados, 14(38): Disponível em: <http://www.scielo.br/scielo.php?script=sci_ arttext\&pid=s0103-40142000000100003> acessado em 15/05/2010.

WÜRTELE, W.; LOBGESANG, H. 1979. Volkswagen in Brasilien - Entwicklungshilfe im Besten Sinne? Bonn; Tübingen, Projektbereich "Dritte Welt" der Arbeitsgemeinschaft Kath. Hochsch.- und Studentengemeinden.

\section{Imprensa}

Autogramm, Wolfsburg, 19/12/1973-01/10/1985, jan. 1987.

BN (Brasilien Nachrichten), Osnabrück, 1. trimestre 1984, $81 / 1983$; 4. trimestre 1984, 84/1984; 2. trimestre 1987, 93/1986.

N.B.: A edição dessa revista sendo irregular, as referências no texto são indicadas por número de edição e não por data $(81 / 1983,84 / 1984$, 93/1986).

Der Spiegel, Hamburgo, 19/1 1/1973, 17/10/1983, 10/11/1986.

Die Grünen Informieren, Hanôver, 12/12/1985.

Die Welt, Berlim, 13/5/1983.

Die Zeit, Hamburgo, 14/12/1973.

Frankfurter Allgemeine Zeitung, Francoforte, 25/09/1979. 
Frankfurter Rundschau, Francoforte, 11/5/1983.

Freiburger Zeitung, Friburgo, 21/10/1985.

Recklinghäuserzeitung, Recklinghausen, 01/12/1982.

Times, Londres, 10/05/1983.

\section{Arquivos:}

Vokswagen, arquivos de empresa, Wolfsburg:

- 65. Sitzung des Aufsichtsrates der Volkswagen AG, 14 nov. 1973, Wolfsburg, in: Unternehmensarchiv $174 / 533 / 2$.

- RICHTER, Dieter, Die Fazenda am Cristalino: Eine Rinderfarm im Gebiet des feuchten Passatwaldes Brasiliens; Ein Film der Volkswagenwerk AG; Lehrerbegleitheft. Wolfsburg : Volkswagenwerk A.G., 1980.

- VOLKSWAGEN A.G., Öffentlichkeitsarbeit, Volkswagen in Brasilien: Ein Report. Wolfsburg, 1973.

- VOLKSWAGEN A.G., Öffentlichkeitsarbeit, Volkswagen - Ein transnationales Unternehmen, Partner der Welt. Wolfsburg, 1980.

- VOLKSWAGEN DO BRASIL S.A., CRISTALINO. Eine Rinderfarm im neuen Viehzuchtgebiet. Wolfsburg, 1983.

- Brochuras não referênciadas.
Arquivos regionais da CPT, Belém do Pará:

- Arquivos não referênciados, Dossiê Santana do Araguaia, cópias.

- Ibid., Dossiê Fazenda Vale do Rio Cristalino, cópias.

- $\quad$ BRÜGGER, F. G. (Companhia Vale do Rio Cristalino). [Carta] 5 jul. 1985, São Paulo [a:] KLEIN, P. (Brasilieninitative), Osnabrück. A propósito de Cristalino.

- DELEGACIA SESP (Conceição do Araguaia), Relatório, 22 jul. 1983.

\section{Outros arquivos:}

- HORNIG, nc, WETZEL, nc, (Volkswagen AG, Wolfsburg). [Carta] 17 jul. 1983 [a:] HAX, T. (Arbeitskreis Dritte Welt), Recklinghausen. A propósito das acusações de Thomas Hax contra a fazenda Cristalino.

- NIEDERSÄCHSISCHER LANDTAG, Politik des Landes gegenüber der Volkswagentochter VW do Brasil - Grosse Anfrage der Fraktion der Grünen vom 19.11.1985, 1985.

- STRÖMEL, H.; HERTERL, H. (Volkswagen, Öffentlichkeitsarbeit). [Carta] 19 dez. 1985, Wolfsburg [a:] BABER, R., lbbenbüren. Resposta aos comentários sobre Cristalino. 